\title{
Gestão democrática do ensino público em municípios piauienses: princípios, espaços e mecanismos de participação $^{1}$
}

\section{Democratic manegement of public education in Piauí municipalites: principles, spaces and mechanisms of participation Gestión democrática de la enseñanza pública en municipios de Piauí: principios, espacios y mecanismos de participación}

RAIMUNDA MARIA DA CUNHA RIBEIRO

Orcid Id: http://orcid.org/0000-0001-6196-731X

Universidade Estadual do Piauí,

\begin{abstract}
Resumo: O objetivo deste estudo é analisar, a partir da legislação de criação dos sistemas municipais de ensino do Piauí, os princípios da gestão democrática, os espaços e os mecanismos de participação. A metodologia adota atributos da pesquisa qualitativa e quantitativa. A técnica de coleta de dados é a análise documental, somando 97 leis. A institucionalização dos sistemas municipais analisados é uma tarefa em processo, o que não poderia ser diferente quanto à materialização da gestão democrática do ensino público.
\end{abstract}

Palavras-chave: Gestão democrática. Ensino público. Municípios.

\begin{abstract}
The aim of this study is to analyze the principles of democratic management, spaces and participation mechanisms, based on the legislation for the creation of municipal education systems in Piaui. The methodology adopts qualitative and quantitative research attributes. The criterion of data collection is the documentary analysis, adding 97 Laws. The institutionalization of the municipal systems analyzed is a task in process, which could not be different regarding the materialization of the democratic management of public education.
\end{abstract}

Keywords: Democratic management. Public education. Counties.

Resumen: El objetivo de este estudio es analizar, a partir de la legislación de creación de los sistemas municipales de enseñanza de Piauí, los principios de la gestión democrática, los espacios y los mecanismos de participación. La metodología adopta atributos de la investigación cualitativa y cuantitativa. La técnica de recolección de datos es el análisis documental, sumando 97 leyes. La institucionalización de los sistemas municipales analizados es una tarea en proceso, lo que no podría ser diferente en cuanto a la materialización de la gestión democrática de la enseñanza pública.

Palabras clave: Gestión democrática. Enseñanza pública. Municipios.

\footnotetext{
1 Parte da etapa estadual de uma pesquisa vinculada à Rede Mapa, uma pesquisa em rede, a qual tem como integrantes os seguintes estados: Rio Grande do Sul, Paraná, Santa Catarina, Tocantins, Maranhão, Piauí, Ceará e Rio de Janeiro. O objetivo principal da Rede Mapa é analisar o quadro normativo e as condições políticoinstitucionais relativas à gestão democrática do ensino público no âmbito dos sistemas municipais de ensino.
} 


\section{INTRODUÇÃO}

No Brasil, a primeira organização de educação, tanto administrativa quanto pedagógica, baseia-se no Ratio Studiorum, cuja proposta se remete a um conjunto de normas, criado para regulamentar a educação nos colégios jesuítas. Com a expulsão dos jesuítas em 1579, e sob o comando do Marquês de Pombal, é construído um novo documento: o Alvará Régio, o qual passa a organizar a educação naquele momento, numa perspectiva lógica, prática e centrada nas relações econômicas. Com a chegada da Família Real, em 1808, fica estabelecida a nova estrutura da educação e o ensino é organizado em três níveis: ensino primário, secundário e superior.

Em 1822, com a proclamação da Independência, e o plano para elaborar a primeira Constituição, o debate em torno da construção de um sistema nacional de instrução pública começa a fazer parte da ordem do dia. Em 1930, com a criação do Ministério da Educação e Saúde Pública, a organização da educação nacional passa por algumas alterações, principalmente, quanto às ações do poder do Estado na efetivação do sistema público de ensino. O período da história do Brasil, denominado Estado Novo (1937 - 1945), toma para a educação os princípios marcados pela tecnocracia e pela ausência de uma política educacional mais democrática, em virtude da pouca abertura política naquele período. Com a promulgação da primeira Lei de Diretrizes e Bases no 4.024/61, mantém-se a estrutura tradicional do ensino, mas como não fixa um currículo nacional, prevê e respeita as particularidades de cada região (GHIRALDELLI JÚNIOR, 2009; LIBÂNEO, 2007; MARTINS, 1991; PARO, 2001, 2007; PENIN; VIEIRA, 2002).

A promulgação da Constituição Federal em 1988 instaura legalmente o Estado democrático de direito, fortalecendo o debate em torno dos direitos humanos, da formação cidadã e do exercício da democracia. O princípio da gestão democrática, definido na Carta (art. 206), reforça o debate sobre a democratização da escola pública e, neste contexto, o município ganha autonomia de organizar seu próprio sistema de ensino. Marco na educação brasileira na década de 1990 é a promulgação da atual LDB n ${ }^{\circ} 9.394 / 96$, que trata, no artigo 14, a respeito da definição das normas da gestão democrática nos sistemas de ensino público. O Plano Nacional de Educação (2001-2011), nos capítulos que trata dos níveis da educação, entre as metas estabelecidas, destaca: criar mecanismos, como conselhos ou equivalentes, para incentivar a participação da comunidade na gestão das escolas. O atual Plano Nacional de Educação (PNE) 2014-2024 (lei no $13.005 / 2014)$ reforça a gestão democrática, no artigo $9^{\circ}$, indicando que os sistemas 
de ensino devam disciplinar a gestão democrática do ensino público, trazendo no corpus da lei a meta 19 e seus desdobramentos em relação à materialização da gestão democrática.

No substrato deste cenário, este estudo traz consigo a seguinte questão orientadora: qual a perspectiva da gestão democrática em municípios piauienses, a partir dos princípios, espaços e mecanismos de participação identificados na legislação de criação dos sistemas municipais de ensino? No sentido de responder a esta pergunta, delineamos os objetivos na seguinte direção: compreender o debate sobre a gestão democrática do ensino público, em consonância com a Constituição Federal de 1988, a LDB de 1996 e o PNE 2014-2024; analisar, a partir da legislação de criação dos sistemas municipais de ensino no âmbito do estado do Piauí, os princípios da gestão democrática, os espaços e os mecanismos de participação; identificar, a partir da legislação analisada, as dimensões da participação na gestão da educação.

A metodologia adota os atributos da abordagem qualitativa e quantitativa. É qualitativa porque propõe analisar e descrever, à luz da legislação de criação dos sistemas municipais de ensino, os conteúdos referentes à gestão democrática, em específico, os princípios, os espaços e os mecanismos de participação. Dizemos que é também quantitativa, porque levantamos a frequência em percentuais dos princípios da gestão democrática, dos espaços e dos mecanismos de participação, em cada uma das mesorregiões geográficas do Piauí. A técnica de coleta de dados é a análise documental e, para tanto, analisamos as leis de institucionalização dos sistemas municipais de ensino do estado do Piaú, somando 97 documentos $^{2}$. A técnica de análise dos dados segue os princípios da análise de conteúdo, segundo as orientações de Bardin (2011): análise de comunicação, visando obter, por procedimentos sistemáticos de descrição de conteúdos de mensagens, indicadores - quantitativos ou não - que permitam a inferência de conhecimentos relativos às condições de produção dessas mensagens. Basicamente, a análise de conteúdo está embasada em três fases: pré-análise, exploração do material e tratamento dos resultados. As categorias de análise são: princípios da gestão democrática, espaços e mecanismos de participação e as dimensões da participação.

As seções nas quais está dividido este artigo discutem os seguintes aspectos: a gestão democrática do ensino público, em especial, na Constituição Federal de 1988, na Lei de Diretrizes e Bases da Educação Nacional de 1996 e no Plano Nacional de Educação de 2014; o cenário da pesquisa; os princípios, os espaços e os mecanismos de participação, com apresentação de mapas, gráficos, tabelas, a partir dos dados extraídos da legislação dos sistemas de ensino em municípios piauienses.

2 Cômputo atualizado em dezembro de 2018. 


\section{ORGANIZAÇÃO DA GESTÃO DO ENSINO PÚBLICO}

Trazemos para a discussão sobre a organização da educação e a gestão democrática do ensino público, fundamentos a partir de três marcos legais: a Constituição Federal de 1988; a Lei de Diretrizes e Bases da Educação Nacional no 9.394/96; e o Plano Nacional de Educação (2014-2024).

A Constituição de 1988 vislumbra a repartição de competências constitucionais referentes à educação, apontando, em alguma medida, para o modelo de federalismo de cooperação, destacando: i) à União compete privativamente legislar sobre as diretrizes e bases da educação nacional; ii) é competência da União, dos Estados, do Distrito Federal e dos Municípios proporcionar meios de acesso à educação; iii) compete à União, aos estados e ao Distrito Federal, concorrentemente, legislar sobre a educação; iv) compete aos municípios manter, sob o regime de colaboração com a União e os estados, programas educacionais na educação infantil e ensino fundamental. A Carta também aprova o princípio da gestão democrática no Art. 206, como forma de garantir a participação e a descentralização do poder decisório em matéria referente ao ensino público; outorga autonomia ao município como ente federado; possibilita a estes criarem seus próprios sistemas de ensino (SOUZA; FARIA, 2004).

A Lei de Diretrizes e Bases da Educação Nacional no 9.394/96, por seu turno, e em conformidade com a Carta de 1988, regulamenta sobre os sistemas de ensino e a responsabilidade de normatizar a gestão democrática e definir as formas de sua materialização, em observância às peculiaridades locais. O Art. $8^{\circ}$ define que "a União, os Estados, o Distrito Federal e os Municípios organizarão, em regime de colaboração, os respectivos sistemas de ensino." (BRASIL, 1996). Tal fundamento recai sobre nosso entendimento que a colaboração entre os sistemas deva se configurar como um regime de articulação e comunicação entre os entes federados. Os artigos $9^{\circ}, 10^{\circ}$ e 11 referem-se às respectivas incumbências da União, estados e municípios sobre a educação. O Art. 14 define os princípios da gestão democrática do ensino público, conforme descrito no próprio caput: "Os sistemas de ensino definirão as normas da gestão democrática do ensino público na educação básica, de acordo com as suas peculiaridades e conforme os seguintes princípios". E os incisos referentes a este artigo tratam da participação em dois mecanismos da gestão democrática: i) participação dos profissionais da educação na elaboração do projeto pedagógico da escola; ii) participação das comunidades escolar e local em conselhos escolares ou equivalentes. Ao se reportar aos sistemas de ensino, o legislador fundamenta a autonomia das unidades escolares públicas em três instâncias: pedagógica, administrativa e financeira, conforme tributa o Art. 15: "Os sistemas de ensino assegurarão às unidades escolares públicas de 
educação básica [...] progressivos graus de autonomia pedagógica e administrativa e de gestão financeira, observadas as normas gerais de direito financeiro público." (BRASIL, 1996).

O Plano Nacional de Educação (2014-2024), disciplinado pela lei $\mathrm{n}^{\circ}$ 13.005/2014, configura-se em um instrumento de planejamento do Estado democrático de direito que orienta a execução e aprimoramento de políticas públicas no setor da educação. No Art. $9^{\circ}$ do PNE, lemos que "Os Estados, o Distrito Federal e os Municípios deverão aprovar leis específicas para os seus sistemas de ensino, disciplinando a gestão democrática" (BRASIL, 2014). Em continuação, especifica o mesmo artigo o prazo de dois anos, adequando, quando for o caso, a legislação local já adotada com essa finalidade.

A meta 19 deste plano trata, em especial, da democratização do ensino público e, para tanto, ressalta o prazo de dois anos, os critérios técnicos de mérito e desempenho, a consulta pública, os recursos e o apoio técnico da União. O desdobramento da meta 19 prevê a abrangência das estratégias, de forma a assegurar a materialização da gestão democrática do ensino público na educação básica. Os elementos que podemos extrair das 8 estratégias são: a) nomeação de diretores e diretoras de escola, considerando, conjuntamente, critérios técnicos de mérito e desempenho, bem como a participação da comunidade escolar; b) programas de apoio e formação aos(às) conselheiros(as) de acompanhamento de políticas públicas educacionais; c) incentivo à constituição de Fóruns Permanentes de Educação; d) constituição e fortalecimento de grêmios estudantis e associações de pais; e) constituição e fortalecimento dos conselhos escolares e conselhos municipais de educação; f) participação na formulação dos projetos políticos-pedagógicos, propostas curriculares, planos de gestão escolar e regimentos escolares; g) garantia da autonomia pedagógica, administrativa e de gestão financeira nos estabelecimentos de ensino; h) programas de formação de diretores e gestores escolares.

Ressaltamos, porém, que a gestão democrática do ensino público implica dispositivos no âmbito dos sistemas em observância às peculiaridades locais, sem, contudo, fugir ao ordenamento jurídico nacional. Antes de adentrarmos na análise da legislação de sistemas municipais de ensino, apresentamos o cenário da pesquisa - municípios piauienses com sistemas de ensino institucionalizados. Tomamos como base a divisão do estado do Piauí em mesorregiões geográficas, assim definidas pelo IBGE: Norte, Centro-Norte, Sudeste, Sudoeste. 


\section{CENÁRIO DA PESQUISA}

\section{Mapa 1 - Percentual de SME institucionalizados no estado do Piauí em 2017}

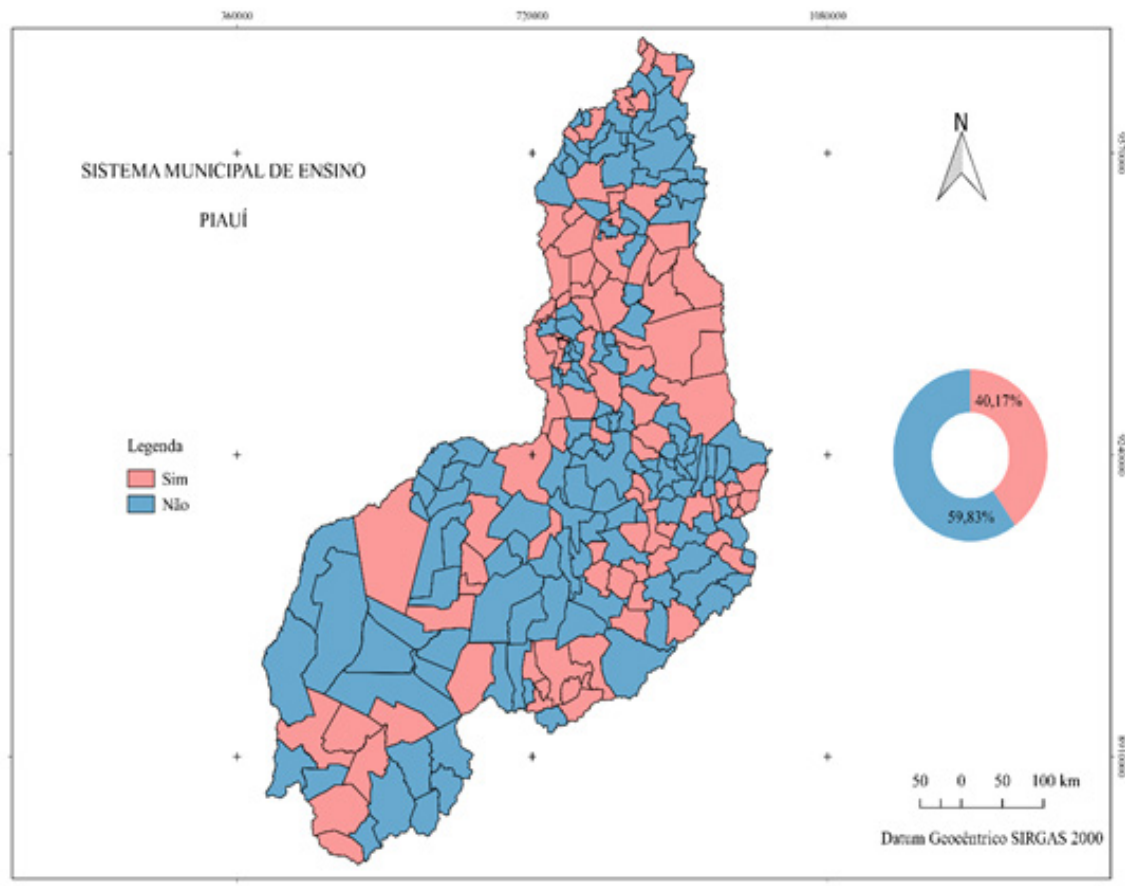

Fonte: Rede Mapa (Coordenação no Piauî).

Para o levantamento sobre os municípios com sistemas próprios de ensino, consideramos dados disponibilizados pelo Conselho Estadual de Educação do Piauí, localizado na cidade de Teresina-PI. Em dezembro de 2017, o estado contava com 90 municípios com sistema institucionalizado (40,17\%), conforme o mapa acima; em dezembro de 2018, contava com 97 municípios com sistema próprio de ensino (43,3\%) do total de 224 municípios.

As exigências para a criação do sistema municipal de ensino no Piaú são: a especificação das competências, a composição e a nomeação do Conselho Municipal de Educação, e a aprovação, pela câmara de vereadores, da lei de criação do Sistema Municipal de Ensino. Em seguida, o Conselho Estadual de Educação é oficialmente comunicado. Este emite uma portaria indicando a institucionalização do sistema e comunica à Secretaria de Estado de Educação e Cultura (Seduc-PI) a desvinculação daquele município do sistema estadual de educação, o qual passa, a partir de então, a gerir o seu sistema de ensino e a política educacional local. 
O Gráfico 1 apresenta a frequência dos municípios com e sem sistema de ensino público institucionalizado no Piauí, identificados por mesorregiões: Norte, Centro-Norte, Sudeste e Sudoeste.

\section{Gráfico 1 - Percentual de SME institucionalizados por mesorregião em 2018}

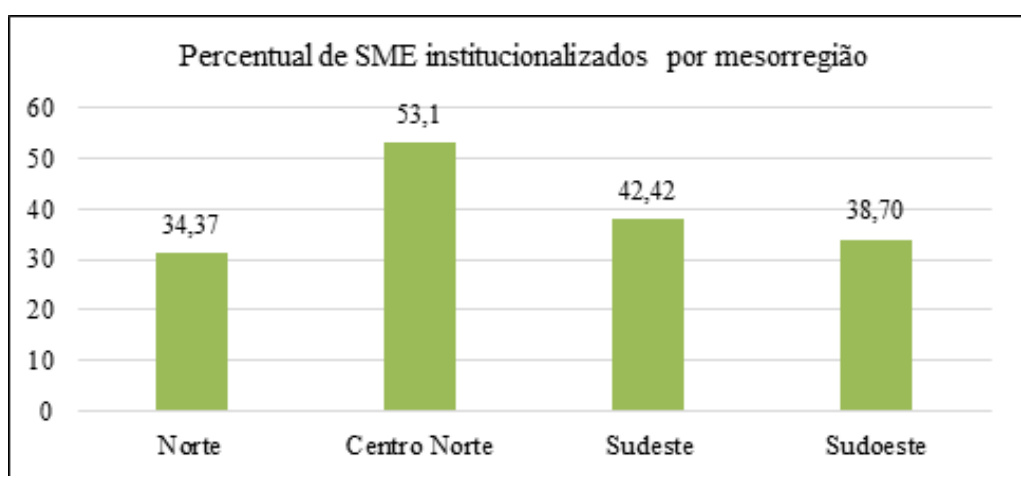

Fonte: Rede Mapa (Coordenação no Piauí).

Os dados apresentados no Gráfico 1 indicam o mesmo retrato do Mapa 1, de modo a identificarmos que o maior número de municípios no estado continua integrado ao sistema estadual via Seduc-PI. A exceção, porém, está em relação à mesorregião Centro-Norte que, ao contrário, tem um número maior de municípios com sistemas próprios de ensino $(56,7 \%)$, quando os integrados ao sistema estadual somam $43,3 \%$. Talvez isso se explique por esta ser a mesorregião onde está localizada a capital do estado, Teresina. Os outros municípios, por estarem geograficamente próximos do Conselho Estadual de Educação (sediado na cidade de Teresina), pode ser que encontrem mais facilidade de comunicação e orientação e, assim, conseguem formalizar o processo de institucionalização dos sistemas de ensino com maior rapidez e eficiência. Esse cenário não nos parece ser especificamente do Piaú, de forma que podemos exemplificar, a partir de dados de uma pesquisa realizada por Cardozo e Colares (2018) sobre a institucionalização de sistemas no estado do Maranhão, que apenas 28 municípios (dos 217) foram identificados com leis de institucionalização aprovadas. Esse cenário é o mesmo do estado do Paraná, onde atualmente apenas 4\% dos municípios já constituíram sistemas próprios de ensino e os demais continuam vinculados ao sistema estadual (FLACH, 2019).

O Sistema Municipal de Ensino é um espaço através do qual os sujeitos locais possam interpretar e participar da política educacional local; é, também, um espaço possível para o entendimento dos traços político-institucionais 
próprios. Por essa razão, a criação das leis referentes à institucionalização dos sistemas pressupõe o exercício da autonomia e a responsabilização dos atores locais (SOUZA; FARIA, 2004; WERLE; THUM; ANDRADE, 2009). A seção seguinte trata, a partir do levantamento das leis de criação dos sistemas municipais de ensino no estado do Piauí, de três aspectos relevantes no contexto da gestão democrática do ensino público em uma das instâncias federadas - o município.

\section{DINÂMICAS DA GESTÃO DEMOCRÁTICA DO ENSINO PÚBLICO EM MUNICÍPIOS PIAUIENSES À LUZ DA LEGISLAÇÃO MUNICIPAL}

Apresentamos, neste contexto, os aspectos anunciados: princípios, espaços e mecanismos de participação, assim como propomos estabelecer, a partir da legislação analisada, as possíveis correlações entre os princípios, os espaços e os mecanismos e as dimensões da participação. Os dados estão dispostos nos Gráficos 2 e 3 e nas Tabelas 1 e 2.

\section{Gráfico 2 - Frequência em relação aos princípios da gestão democrática por mesorregião geográfica do estado do Piauí em 2018 SUGIRO RETIRAR TÍTULO DE DENTRO DA ILUSTRAÇÃO E CONSERTAR "CENTRO-NORTE"}
Frequência em relação aos principios da gestão democrática por mesorregião geográfica do estado do Piaui

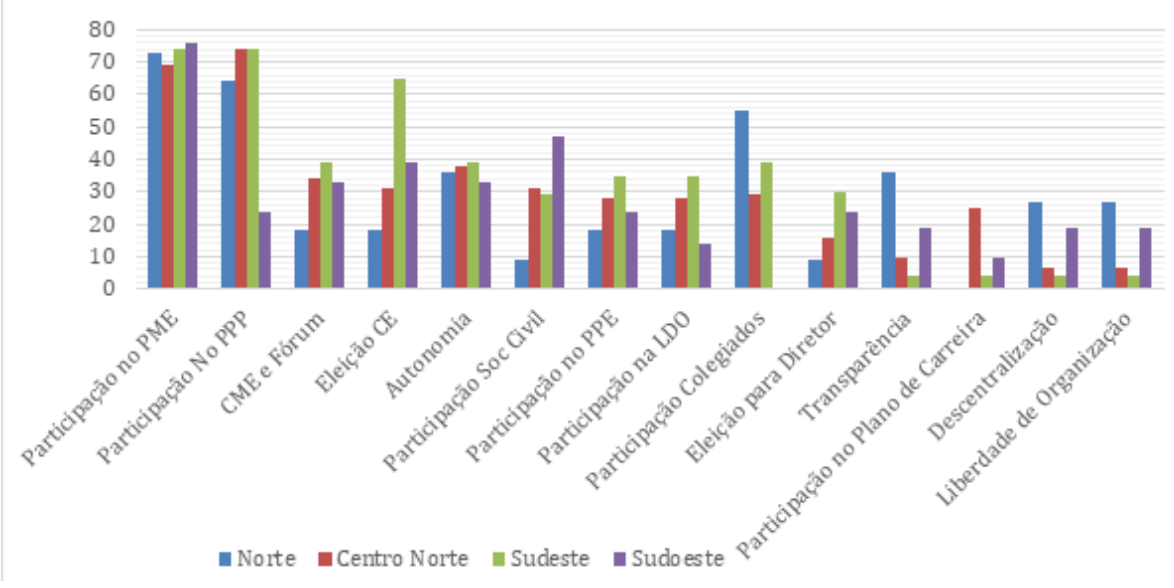

Fonte: Rede Mapa (Coordenação no Piauî). 
O Gráfico 2 permite identificar os princípios da gestão democrática extraídos da legislação municipal. Consideramos, entretanto, que em um universo de 97 leis de criação dos sistemas municipais de ensino no Piauí, há um percentual de $35 \%$ destas que não trazem em seu corpus o dispositivo da gestão democrática. Nosso entendimento é de que boa parte dos sistemas municipais materializa a gestão (democrática), considerando outros dispositivos, para além da própria lei que os instituiu, como, por exemplo, a CF de 1988, a LDB de 1996 e o PNE 2014-2024. Os princípios se apresentam em baixa frequência, de modo que podemos identificar, na legislação analisada, uma projeção acima de 50\%, a participação em apenas quatro instâncias da gestão: participação na elaboração do Plano Municipal de Educação; participação na elaboração do projeto políticopedagógico; eleição do Conselho Escolar (mesorregião Sudoeste); participação nos colegiados (mesorregião Norte). Os dados nos permitem interpretar e inferir que há uma lacuna entre o proclamado pelos documentos em nível nacional (CF, LDB, PNE) e o declarado nas leis de institucionalização dos sistemas de ensino analisadas, acerca da participação na política educacional no âmbito local.

$\mathrm{Na}$ esteira deste debate, citamos um estudo realizado por Ribeiro, Iziquierdo e Santos (2012), no qual os autores reconhecem que a capacidade de gestão democrática implica a competência das municipalidades de não apenas garantir a capacidade de descentralização, mas, também, a capacidade de participação e de transparência. Nardi, Rebelatto e Gamba (2013), ao investigarem sobre gestão do ensino público, concluem que a implementação de políticas e de organização do trabalho coletivo é um processo que ocorre sob determinada orientação política, consoante à dinâmica das relações que se desenvolvem em sociedade. Outro exemplo que cabe nesta discussão são as conclusões de um estudo realizado por Lima, Aranda e Lima (2012), nas quais os autores ressaltam que o significado do princípio da participação vem indicando que a democracia não tem conseguido se articular a uma concepção que legitime seus valores, e, empiricamente, argumentam que a participação é reduzida, controlada e regulada. E mais um estudo nesta direção nos indica que para a institucionalização do sistema de ensino é necessário que a gestão municipal se disponha a romper com o caráter de base patrimonial presente na prática governamental, porque não há garantia de democratização da gestão somente mediante a institucionalização do sistema de ensino, sem que haja um processo de construção da gestão pública assentado no coletivo. Esse processo demanda, pois, mecanismos que viabilizem a participação da sociedade nas deliberações sobre a política educacional local (PEREIRA, 2010). 
Importa dizer que, embora a gestão democrática esteja assegurada na forma da lei, o debate em torno de sua institucionalização e implantação nos sistemas de ensino e nas escolas públicas tem destacado alguns desafios quanto à sua materialização, entre os quais podemos citar: o modelo gerencialista na gestão da educação, a competência das municipalidades, a orientação política, e o princípio da participação na gestão democrática. No estado do Piauí, os dados têm demonstrado traços semelhantes aos estudos citados, de forma que podemos identificar no conjunto das leis analisadas que: o princípio da participação é pouco identificado nos textos, nos levando a entender que o município não construiu a capacidade de descentralização de forma plena; a política de centralização está, em alta medida, atrelada à organização da gestão; o modelo de gestão proclamado nos documentos nacionais, como uma forma de materializar a democracia no âmbito dos sistemas de ensino, não tem conseguido se articular com as particularidades locais e as concepções político-administrativas do município.

Após a identificação dos princípios da gestão democrática e a frequência com que ocorrem na legislação, passamos a fazer o mesmo em relação aos espaços e mecanismos de participação.

Gráfico 3 - Frequência em relação aos espaços e mecanismos da participação na gestão democrática por mesorregião geográfica do estado do Piauí em 2018.

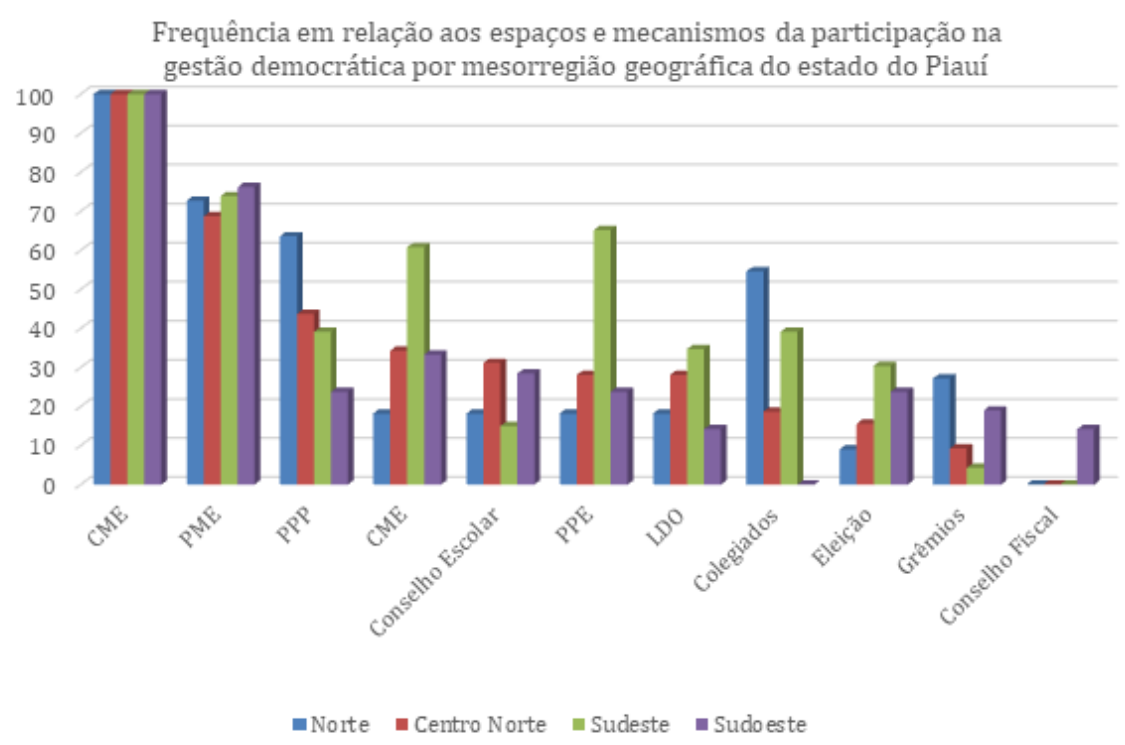

Fonte: Rede Mapa (Coordenação no Piauî). 
Podemos identificar os espaços e mecanismos de participação, conforme Gráfico 3, a partir de três dimensões: i) Poder decisório: Conselho Municipal de Educação, Conselho Escolar, órgãos colegiados, grêmios e Conselho Fiscal, Conferência Municipal de Educação; ii) Planejamento: Plano Municipal de Educação; projeto político-pedagógico; Plano Plurianual de Educação; Lei de Diretrizes Orçamentárias; iii) Democracia representativa: Eleição da equipe diretiva. De posse dos dados podemos constatar que o único espaço de participação democrática presente 100\% no corpus das leis é o Conselho Municipal de Educação, condição sine qua non para a institucionalização do sistema de ensino. Acima de 50\% podemos identificar: Plano Municipal de Educação, projeto político-pedagógico (mesorregião Norte), Conferência Municipal de Educação (mesorregião Sudeste), Plano Plurianual de Educação (mesorregião Norte). Interpretamos que a baixa frequência dos espaços e mecanismos de participação na gestão pode estar relacionada ao fato de que a construção da democracia nos sistemas de ensino é resultado de um processo relativamente lento de aprendizado político.

O conjunto da legislação analisada nesta investigação, a exemplo de estudo realizado por Werle, Thum e Andrade (2009), permite-nos identificar que as oportunidades de criação de novos caminhos e de processos de interação social nos sistemas municipais de ensino existem, embora possam não estar imprimindo os anseios da sociedade em relação à democratização da educação. Nessa direção, tomamos como exemplo um estudo realizado por Maranhão e Marques (2014) sobre os mecanismos de participação social nas escolas da rede municipal do Jaboatão dos Guararapes, da Região Metropolitana do Recife - embora estejamos tratando de sistema - no qual suas conclusões coadunam com nossas inferências, de forma que apontam para o reconhecimento da fragilidade da cultura democrática identificada nos sujeitos contemplados no estudo. O estudo recente de Nardi (2018) trata dos mecanismos de participação e possíveis arranjos institucionais patrocinados por sistemas municipais de ensino no estado de Santa Catarina e nos permite considerar as dimensões comuns às condições político-institucionais para a promoção da participação e democratização da gestão educacional, bem como indícios da configuração de arranjos institucionais com potencial de reforço à democratização da gestão do ensino público em nível de sistema e de escola. O referido estudo conclui que serão os usos dos mecanismos dos arranjos institucionais que demarcarão a efetividade das ações no campo democrático, devendo estar em causa como esses mecanismos são traduzidos pelos sujeitos sociais enquanto ferramentas de participação e decisão - esta é uma das razões que afirmamos que a democratização da gestão dos sistemas de ensino é uma tarefa e um aprendizado em processo. 
Assim posto, concordamos com os estudos citados, de que a participação é a principal ferramenta para assegurar a efetividade da gestão democrática da educação, de modo a possibilitar o envolvimento e a corresponsabilidade dos sujeitos sociais na elaboração, implementação e avaliação da política educacional local.

As Tabelas 1 e 2, apresentadas a seguir, permitem identificar, respectivamente, a correlação entre as dimensões da participação e os princípios da gestão democrática, assim como a correlação entre as dimensões da participação e os espaços e os mecanismos.

\section{Tabela 1 - Frequência dos princípios da gestão democrática relacionados às dimensões da participação em 2018}

\begin{tabular}{|c|c|c|}
\hline \multirow{2}{*}{ Dimensões } & \multirow{2}{*}{ Princípios } & Frequência (\%) \\
\hline & & Total-Piauí \\
\hline \multirow{5}{*}{ Poder decisório } & Autonomia das escolas na gestão pedagógica, administrativa e financeira & $36,8 \%$ \\
\hline & Participação da comunidade, dos conselhos e da sociedade civil & $34,5 \%$ \\
\hline & $\begin{array}{l}\text { Participação na elaboração e atualização no Plano de Carreira, Cargos } \\
\text { e Salários }\end{array}$ & $12,7 \%$ \\
\hline & Liberdade de organização dos segmentos da comunidade escolar & $10,3 \%$ \\
\hline & Conferência Municipal de Educação como fórum máximo de deliberação & $39,1 \%$ \\
\hline \multirow{4}{*}{ Planejamento } & $\begin{array}{l}\text { Participação na elaboração e atualização do Plano Municipal de } \\
\text { Educação }\end{array}$ & $72,4 \%$ \\
\hline & $\begin{array}{l}\text { Participação dos profissionais da educação, pais e responsáveis na } \\
\text { elaboração do projeto político-pedagógico }\end{array}$ & $41,4 \%$ \\
\hline & Participação na elaboração do Plano Plurianual de Educação & $27,5 \%$ \\
\hline & $\begin{array}{l}\text { Participação na elaboração do Orçamento Municipal da Educação e na } \\
\text { Lei de Diretrizes Orçamentárias }\end{array}$ & $25,3 \%$ \\
\hline \multirow{2}{*}{$\begin{array}{l}\text { Democracia } \\
\text { representativa }\end{array}$} & Eleição direta para o Conselho Escolar & $37,9 \%$ \\
\hline & Realização de eleição direta para a direção de escolas & $20,6 \%$ \\
\hline
\end{tabular}

Fonte: Rede Mapa (Coordenação no Piaui).

Pelos dados apresentados, nenhum dos princípios identificados no conjunto da legislação analisada atinge a frequência de 50\%, nem mesmo os disciplinados no Art. 14 da LDB no 9394/96: participação na elaboração do projeto político-pedagógico $(41,4 \%)$ e participação das comunidades em conselhos escolares e equivalentes $(34,5 \%)$. Os níveis e as variadas formas de participação, identificados na Tabela 1 , circunscrevem-se à defesa de interesses políticos específicos e à natureza do projeto social e educacional de cada sistema de ensino. 
Os dados referidos realçam os dados advindos de um estudo realizado por Souza e Faria (2004) sobre a municipalização do ensino no Brasil que, em face da atribuição de progressivos graus de autonomia deferidos aos municípios, estes se veem diante de desafios concernentes à participação no regime de colaboração, na elaboração dos Planos Municipais de Educação, na constituição dos Conselhos Municipais de Educação, no acompanhamento e controle social e na instituição dos fóruns permanentes de educação. Nessa perspectiva, interpretamos que o conceito de participação na gestão democrática do ensino público, compreendido pelos sistemas de ensino, tem assumido um caráter reducionista, distanciado do conceito de participação em sua forma plena.

A necessidade de ampliação da participação no âmbito dos sistemas municipais de ensino não se refere apenas à realidade circunscrita ao estado do Piauí, visto que outros estudos apontam em suas considerações cenários semelhantes. De acordo com as análises apresentadas por Rebelatto e Nardi (2012), sob a ótica de um estudo realizado em municípios catarinenses, tendo em vista o pressuposto da participação da comunidade nos processos decisórios acerca de assuntos educacionais, consideram que as opções político-institucionais traduzem um quadro preocupante. A pesquisa traz dados que nos possibilitam constatar que, embora a maioria dos municípios possua sistema próprio de ensino, os princípios da gestão democrática do ensino público não representam maiores avanços em relação ao mínimo firmado na $\mathrm{LDB} / 96$, na medida em que não apontam para o alargamento em relação ao definido pela legislação nacional.

Assim posto, reconhecemos, por um lado, que o sistema de ensino é um espaço de lutas e de conflitos, visto que sua organização e difusão, ao longo dos séculos, refletem forças econômicas, históricas e sociais em seu entorno e, por outro lado, esse mesmo sistema também carrega e alimenta esperanças de democratização social e de libertação dos povos (SARMENTO, 2005). É nesse sentido que postulamos a crença de que há pertinência no debate em torno do conceito e efeito da gestão democrática do ensino público.

Apresentada a correlação dos princípios da gestão democrática com as dimensões da participação (poder decisório, planejamento e democracia representativa), passamos, então, à apresentação da correlação dessas dimensões com os espaços e os mecanismos da participação, conforme está demonstrado na Tabela 2. 


\section{Tabela 2 - Frequência dos espaços e mecanismos da gestão democrática relacionados às dimensões da participação em 2018}

\begin{tabular}{|c|c|c|}
\hline \multirow{3}{*}{ Dimensões } & Espaços e mecanismos & Frequência (\%) \\
\cline { 2 - 3 } & Conselho Municipal de Educação & Total-Piauí \\
\hline \multirow{4}{*}{ Poder decisório } & Conferência Municipal de Educação & 100 \\
\cline { 2 - 3 } & Conselho Escolar & 39,1 \\
\cline { 2 - 3 } & Órgãos Colegiados & 37,9 \\
\cline { 2 - 3 } & Grêmios & 24,1 \\
\cline { 2 - 3 } & Conselho Fiscal & 12,6 \\
\cline { 2 - 3 } & Plano Municipal de Educação & 3,4 \\
\hline \multirow{3}{*}{ Planejamento } & Projeto Político-Pedagógico & 72,4 \\
\cline { 2 - 3 } & Plano Plurianual de Educação & 40,2 \\
\cline { 2 - 3 } & Lei de Diretrizes Orçamentárias & 27,6 \\
\cline { 2 - 3 } & Eleição da equipe diretiva & 20,3 \\
\hline \multirow{2}{*}{$\begin{array}{c}\text { Democracia } \\
\text { representativa }\end{array}$} & & 20,7 \\
\hline
\end{tabular}

Fonte: Rede Mapa (Coordenação no Piauî).

A Tabela 2 traz alguns dados acerca da participação na gestão democrática de acordo com o que dispõem as leis analisadas e nos permitem afirmar que: o Conselho Municipal de Educação está presente em 100\% das leis, pois é uma prerrogativa para institucionalização do sistema; há uma variedade em termos de frequência dos espaços apresentados, ou seja, enquanto o Plano Municipal de Educação tem frequência de 72,4\%, o Conselho Fiscal computa somente 3,4\%; os espaços de participação são pouco explicitados nas leis, mesmo os recomendados pela LDB/96, em conformidade com o Art. 14.

Os dados demonstram baixa frequência em relação aos espaços e mecanismos, mas, ainda assim, nossas análises nos remetem à reflexão de que a participação é o melhor caminho para a gestão da educação e, ancorados nas ideias de Bordenave (1985), este ideário traz consigo mais pontos positivos que do contrário, pois: facilita o crescimento da consciência crítica da população; fortalece seu poder de reivindicação; prepara para adquirir mais poder na sociedade; garante o controle das autoridades por parte do povo; quando a população participa da fiscalização dos serviços públicos, estes tendem a melhorar em qualidade e oportunidade.

O que falta, afinal, para a sociedade se envolver de forma plena da gestão do ensino público? Os espaços e mecanismo de participação na gestão do ensino existentes são suficientes? Embora sem pretendermos indicar respostas totais para essas perguntas, nos limitamos a realçar que a democracia participativa é 
aquela em que os cidadãos sentem que, por participarem, têm responsabilidades e, por isso, tomam parte na construção de uma nova sociedade (BORDENAVE, 1985). É nesse caminho que queremos o ensino público.

\section{CONCLUSÕES}

Este estudo foi construído com o objetivo de compreender a gestão democrática do ensino público à luz de dispositivos legais, como a Carta Federal de 1988 (Art. 206), a LDB de 1996 (Art. 14) e o PNE 2014-2024 (Meta 19) e, a partir desse entendimento, fazer o levantamento, seguido de análise do conjunto de leis de criação dos sistemas de ensino institucionalizados nos municípios do estado do Piauí, com ênfase nos princípios da gestão democrática e nos espaços e mecanismos de participação e, ainda, fazer uma correlação destes com três dimensões (poder decisório, planejamento e democracia participativa), as quais emergiram das próprias leis.

O estudo, do ponto de vista teórico, com base na legislação nacional acerca da matéria da educação, permitiu-nos compreender: a gestão democrática do ensino público não é somente um princípio constitucional, mas uma necessidade; a participação social é o mais valioso princípio da gestão democrática; é possível termos acesso aos espaços e mecanismos de participação na gestão tanto dos sistemas, quanto das escolas.

Partindo desse entendimento, realizamos uma análise nas leis de criação dos sistemas de ensino de municípios piauienses, de forma a identificar os princípios da gestão democrática, os espaços e mecanismos de participação. Com base na forma como a legislação apresenta tais princípios, foi possível identificar três dimensões em que estão diretamente correlacionados, assim como estão com os espaços e mecanismos de participação: i) poder decisório: os conselhos, os colegiados e os fóruns, grêmios; ii) planejamento: plano municipal de educação, projeto político-pedagógico, plano plurianual de educação, lei de diretrizes orçamentárias; iii) democracia representativa: eleição para diretores e conselho escolar.

E para concluirmos, acreditamos que o reconhecimento de mudanças na organização e gestão educacional, conforme argumentam Nardi, Rebelatto e Gamba (2013), reforça a possiblidade de os municípios trilharem o caminho da transformação da realidade local, de forma a promover maior compasso entre a própria realidade e as expectativas de desenvolvimento educacional. A autonomia, portanto, assegurada aos municípios pelas vias da institucionalização dos sistemas de ensino, reforça, sobremaneira, essa possibilidade. 
Dizemos, desta feita, que a institucionalização dos sistemas municipais de ensino do estado do Piaú é uma tarefa em processo, o que não poderia ser diferente quanto à materialização da gestão democrática do ensino público.

\section{REFERÊNCIAS}

BARDIN, Laurence. Análise de conteúdo. Lisboa: 70-LDA, 2011.

BORDENAVE, Juan Diaz. O que é participação. São Paulo: Brasiliense, 1985.

BRASIL. Constituição Federal. Brasília, DF: Senado Federal, 1988.

BRASIL. Lei de Diretrizes e Bases da Educação no 4024/61. Brasília, DF: Senado Federal, 1961.

BRASIL. Lei de Diretrizes e Bases da Educação nº 9394/96. Brasília, DF: Senado Federal, 1996.

BRASIL. Lei n. 010.172, de 9 de janeiro de 2001. Aprova o Plano Nacional de Educação - PNE e dá outras providências. Brasília: Presidência da República/ Casa Civil. Disponível em: http://www.planalto.gov.br/ccivil_03/_ato20112014/2014/lei/113005.htm . Acesso em: 20 jul. 2017.

BRASIL. Lei n. 13.005, de 25 de junho de 2014. Aprova o Plano Nacional de Educação - PNE e dá outras providências. Brasília: Presidência da República/ Casa Civil. Disponível em: http://www.planalto.gov.br/ccivil_03/_ato20112014/2014/lei/113005.htm . Acesso em: 20 jul. 2017.

CARDOZO, Maria José Pires Barros; COLARES, Maria Lília Imbiriba Sousa. Sistemas municipais de educação: autonomia e gestão democrática como premissas. Revista Tempos e Espaços em Educação, v. 11, n. 01, Edição Especial, p. 351-362, dezembro, 2018.

FLACH, Simone de Fátima. A gestão democrática nos sistemas municipais de ensino do Paraná: uma análise a partir dos conselhos municipais de educação. Ensaio: aval. pol. públ. Educ., v. 27, n. 102, p 1-20, Rio de Janeiro, 2019.

GHIRALDELLI JÚNIOR, Paulo. História da educação brasileira. São Paulo: Cortez, 2009. 
LIBÂNEO, José Carlos. Concepções e práticas de organização e gestão da escola: considerações introdutórias para um exame crítico da discussão atual no Brasil. Revista Española de Educación Comparada, Madrid: Espanha, n. 13, p. 155192, 2007.

LIMA, Paulo Gomes; ARANDA, Maria Alice de Miranda.; LIMA, Antônio Bosco de. Políticas educacionais, participação e gestão democrática da escola na contemporaneidade brasileira. Rev. Ensaio, Belo Horizonte, v. 14, n. 1, p. 51-64, jan./abr. 2012.

MARANHÃO, Iágrici Maria de Lima; MARQUES, Luciana Rosa. Os mecanismos de participação social na escola: instrumentos de gestão democrática ou de controle? Espaço do currículo, v.7, n. 1, p. 125-136, jan./abr. 2014.

MARTINS, José do Prado. Administração escolar: uma abordagem crítica do processo administrativo em educação. São Paulo: Atlas, 1991.

NARDI, Elton.; REBELATTO, Durlei Maria Bernardon; GAMBA, Ivan Carlos. Opções político-institucionais de sistemas municipais de ensino: para onde caminha a gestão democrática do ensino público? Roteiro, Joaçaba: Ed. Unoesc, v. 38, n. 1, p. 169-194, jan./jun. 2013.

NARDI, Elton Luiz. Gestão democrática do ensino público na educação básica: dimensões comuns e arranjos institucionais sinalizados em bases normativas de sistemas municipais de ensino. Educar em Revista, Curitiba, Brasil, v. 34, n. 68, p. 123-136, mar./abr. 2018.

PARO, Victor Henrique. Administração escolar: introdução crítica. 10. ed. São Paulo: Cortez, 2001.

PARO, Victor Henrique. Gestão escolar, democracia e qualidade do ensino. São Paulo: Ática, 2007.

PENIN, Sonia T. Sousa; VIEIRA, Sofia Lerche. Refletindo sobre a função social da escola. In: VIEIRA, Sofia Lerche (Org.). Gestão da escola: desafios a enfrentar. Rio de Janeiro: DP\&A, 2002. p. 13-43. 
PEREIRA, Maria do Socorro Vasconcelos. A institucionalização dos sistemas municipais de ensino na realidade paraense: obstáculos e possibilidades - o caso do município de Barcarena. 2010.191 f. Dissertação (Mestrado em Educação) - Universidade Federal do Pará, Instituto de Ciências da Educação, Belém, 2010.

REBELATTO, Durlei Maria Bernardon; NARDI, Elton Luiz. Gestão democrática do ensino público: uma leitura das opções político-institucionais nos sistemas municipais de ensino do oeste catarinense. IX ANPED SUL. Seminário de Pesquisa em educação da região Sul, 2012.

RIBEIRO, Elizabeth Matos; IZIQUIERDO, Oscar Chassagnes; SANTOS, Reginaldo Souza Avaliação da capacidade de gestão democrática em municípios baianos. O\&S, Salvador, v. 19, n. 63, p. 717-736, out./dez. 2012. Disponível em: <www.revistaoes.ufba.br>. Acesso em: 14 mar. 2016.

SARMENTO, Dilva Chaves. Criação dos sistemas municipais de ensino. Educ. Soc., Campinas, v. 26, n. 93, p. 1363-1390, set./dez. 2005. Disponível em: < http:/ / www.cedes.unicamp.br>. Acesso em: 20 set. 2017.

SOARES, Márcia Miranda. Teoria do sistema federal: heterogeneidades territoriais, democracia e instituições políticas. 1997. Dissertação (Mestrado em Ciência Política) - Universidade Federal de Minas Gerais, Belo Horizonte, 1997.

SOUZA, Donaldo Bello; FARIA, Lia Ciomar Macedo de. Reforma de Estado, descentralização e municipalização do ensino no Brasil: a gestão política dos sistemas públicos de ensino pós-LDB 9.394/96. Ensaio: aval. pol. públ. Educ., Rio de Janeiro, v. 12, n. 45, p. 925-944, out./dez. 2004.

VIEIRA, Sofia Lerche e VIDAL, Eloisa Maia. Gestão democrática da escola no Brasil: desafios à implantação de um novo modelo. Revista Ibero-Americana de Educação, n. 67, p. 19-37, jan./abr. 2015.

WERLE, Flávia. Obino Corrêa.; THUM, Adriane Brill.; ANDRADE, Alenis Cleusa de. Processo nacional de avaliação do rendimento escolar: tema esquecido entre os Sistemas Municipais de Ensino. Ensaio: aval. pol. públ. Educ., Rio de Janeiro, v. 17, n. 64, p. 397-420, jul./set. 2009. 


\section{Raimunda Maria da Cunha Ribeiro}

Doutora em Educação (PUCRS), tendo realizado estágio pós-doutoral no PPGDE-UNOESC. Professora da Universidade Estadual do Piauí, do curso de Pedagogia. E-mail: raicribeiro@hotmail.com.

Recebido em 22 de agosto 2019. Aprovado em 19 de fevereiro 2020. 